\title{
Advanced Neurotechnologies for Chronic Neural Interfaces: New Horizons and Clinical Opportunities
}

\author{
Daryl R. Kipke, ${ }^{1,6}$ William Shain, ${ }^{2}$ György Buzsáki, ${ }^{3}$ E. Fetz ${ }^{4}$ Jaimie M. Henderson, ${ }^{5}$ Jamille F. Hetke, ${ }^{6}$ and \\ Gerwin Schalk ${ }^{2}$ \\ ${ }^{1}$ Department of Biomedical Engineering, University of Michigan, Ann Arbor, Michigan 48109, ${ }^{2}$ Wadsworth Center, New York State Department of Health, \\ Albany, New York 12201, ${ }^{3}$ Center for Molecular and Behavioral Neuroscience, Rutgers, The State University of New Jersey, Newark, New Jersey 07102 , \\ ${ }^{4}$ Department of Physiology and Biophysics, University of Washington, Seattle, Washington 98195, ${ }^{5}$ Stereotactic and Functional Neurosurgery, Stanford \\ University School of Medicine, Stanford, California 98195, and ${ }^{6}$ NeuroNexus Technologies, Ann Arbor, Michigan 48108
}

Key words: neural prosthetics; brain-computer interfaces; neural interface technologies; electrocorticogram; microelectrode array; cortical recording

\begin{abstract}
Introduction
Technological advances in neural interfaces are providing increasingly more powerful "toolkits" of designs, materials, components, and integrated devices for establishing high-fidelity chronic neural interfaces. For a broad class of neuroscience studies, the primary requirements of these interfaces include recording and/or stimulating from a number of discretely sampled volumes at requisite spatial resolutions for specific periods of time. Translational and clinical applications present additional requirements for safety, usability, reliability, patient acceptance, and cost effectiveness. Innovative solutions result from the constructive tension between ever-increasing application requirements and incorporation of technological advances into usable devices. The purpose of this minireview is to present snapshots of the current state-of-the-art in chronic, microscale neural interfaces by highlighting several leading neuroscience applications and discussing their implications for next-generation interface devices.
\end{abstract}

\section{Advances in neural interface technologies}

Neural interface devices have a large design space in terms of size, shape, and function. Distinct and diverse neural targets prohibit a one-size-fits-all approach. Considering implantable, chronic microelectrode arrays for recording, which typically have the most rigorous requirements for selectivity, sensitivity, precision, and longevity, three of the principal design considerations are (1) spatial and temporal resolution of desired signals (e.g., synaptic currents, single units, and field potentials), (2) number and placement of the electrode sites, and (3) functional lifetime of the device. A growing number of wire and microfabrication electrode technologies intended to meet these requirements are in various

Received Aug. 14, 2008; revised Sept. 26, 2008; accepted 0ct. 4, 2008.

This work was supported by National Institutes of Health Grants EB 002030 (D.R.K., W.S.), NS12542 and RR00166 (E.F.), NS044287 (W.S.), NS060269 and NS054346 (J.H.), and EB006356 and EB000856 (G.S.), and by United States Army Research Office Grants W911NF-07-1-0415 and W911NF-08-1-0216 (G.S).

D.R.K. has financial and leadership interests in NeuroNexus Technologies.

Correspondence should be addressed to Daryl R. Kipke, Department of Biomedical Engineering, 2212 LBME, 1101

Beal Avenue, University of Michigan, Ann Arbor, Ml 48109. E-mail: dkipke@umich.edu.

DOI:10.1523/JNEUROSCI.3879-08.2008

Copyright $\odot 2008$ Society for Neuroscience ～0270-6474/08/2811830-09\$15.00/0 stages of development (McNaughton et al., 1983; Nordhausen et al., 1996; Hetke and Anderson, 2002; Nicolelis et al., 2003; Wise et al., 2004; Motta and Judy, 2005; Rennaker et al., 2005; McCreery et al., 2006; Musallam et al., 2007; Neves and Ruther, 2007; Bartels et al., 2008). As a group, these devices have enabled successive advances in highly parallel recording of signals from synaptic currents to single units to local fields through systematic refinements of materials, fabrication processes, packaging, and usage. Wire bundles and arrays are the simpler technology and are the most widespread type of implantable electrode array.

Microfabricated electrode arrays (neural probes) formed by lithographic patterning of thin films of conductors and insulators on silicon or polymer substrates involve more complex technologies, but have the benefit of accessing a larger design space. Microfabricated probes can be readily customized to meet specific experiment requirements. In a silicon technology (Hetke and Anderson, 2002), for example, the probe can have almost any two-dimensional shape with single or multiple shanks (Fig. $1 A, B)$. Electrode sites can be realized from a variety of materials, can have a range of surface areas, and can be placed anywhere along the shank(s) at any spacing; tips can be made very sharp or blunt; and features such as holes and barbs can be included. The high-quality, commercial-grade microfabricated probes that are available today are the result of steady advances in design rules, lithography, substrates, thin-film organic and inorganic dielectric materials, metal deposition, packaging, and quality control.

Proof of concept for obtaining high-quality unit recordings for more than several months has been established through independent studies from several labs that collectively cover diverse types of microelectrode arrays implanted in rat, cat, and nonhuman primate (Rousche and Normann, 1998; Liu et al., 1999; Kipke et al., 2003; Nicolelis et al., 2003; McCreery et al., 2004; Suner et al., 2005; Jackson and Fetz, 2007). However, there is a large degree of variability and unpredictability in chronic performance that results from an incomplete understanding of the failure (and success) modes of implantable microscale devices. At present, the state of the art for implantable arrays is that recording quality typically degrades and uniformly fails over time (lifetimes ranging from several weeks to several months). Scientific 

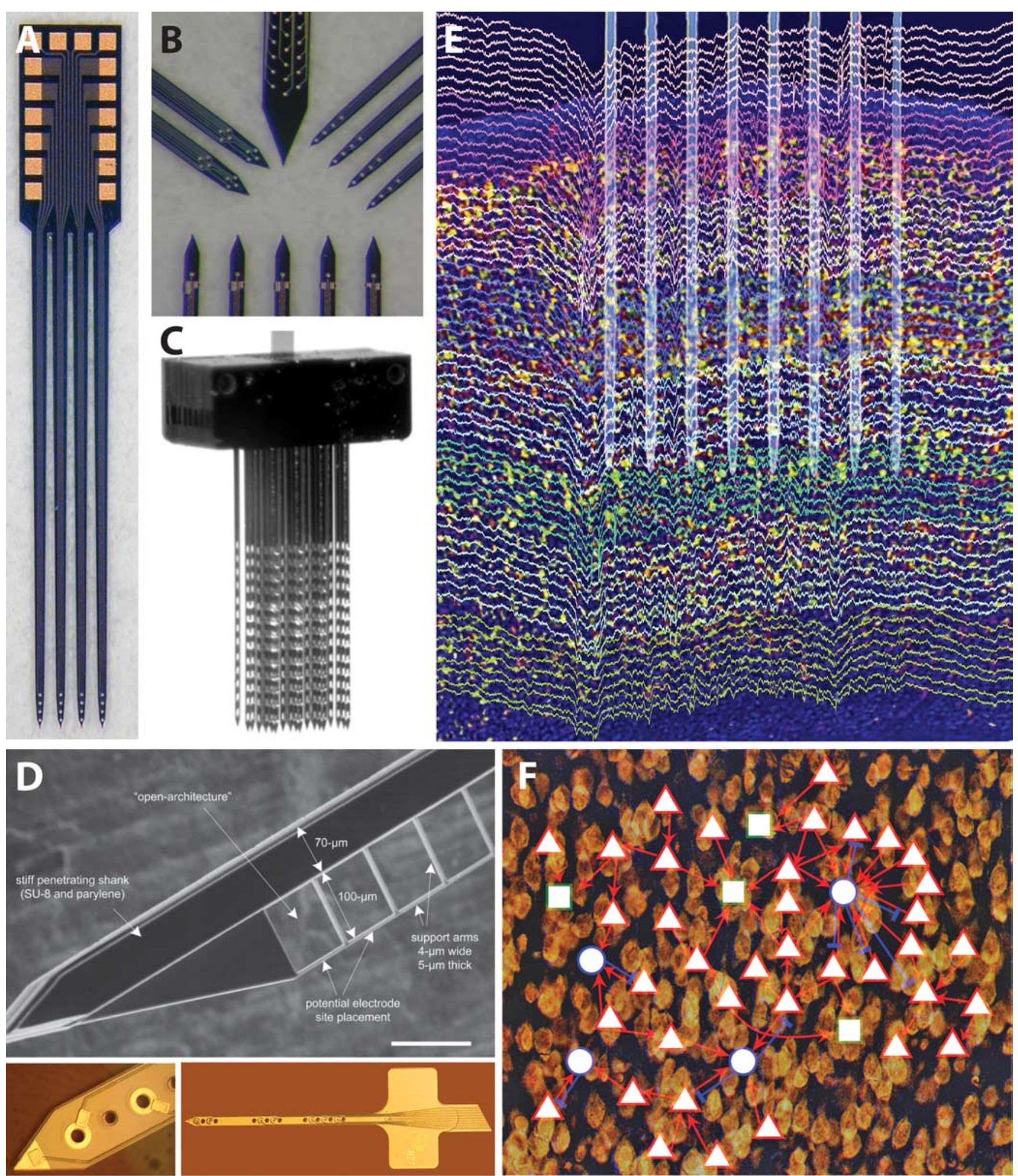

Figure 1. $\boldsymbol{A}$, Photograph of a four-shank silicon neural probe having four electrode sites arranged near the tip, each terminated in a bond pad at the tab (NeuroNexus Technologies). $\boldsymbol{B}$, High-magnification photographs illustrating four different types of sites layouts for specialized interfaces (NeuroNexus Technologies). C, Photograph of a modular 128-site, three-dimensional array made from several multishank planar arrays (NeuroNexus Technologies). D, Open architecture probe designs to improve tissue integration [Seymour and Kipke (2007), their Fig. 1A]. E, High-density recording of unit activity in rat neocortex. The placement of an eight-shank silicon device in layer $V$ is overlaid on recordings color coded for different electrodes. Note the presence of spikes on several sites of the same shank and lack of the same spikes across the different shanks, indicating that electrodes placed $\geq 200 \mu \mathrm{m}$ laterally record from different cell populations. Spikes and local field potentials are both visible in this wide-band ( $1 \mathrm{~Hz}$ to $10 \mathrm{kHz}$ ) recording (Fujisawa et al., 2008). Modified from Buzsáki (2004), his Figure 2A, reprinted with permission. F, Demonstration of functional connectivity in the cortex of behaving animals. A small network of pyramidal cells (red triangles) and putative inhibitory interneurons (blue circles) in layer $V$ of the prefrontal cortex of the rat are mapped. Rectangles are unidentified units. Note a large "hub" formed by an interneuron and its multiple partners [Fujisawa et al. (2008), their supplemental Fig. 11]. 
advances in understanding the chronic electrode-tissue interface are fueling innovative new approaches for longer-lasting electrode arrays. For example, advanced probe architectures (Fig. 1D) (Seymour and Kipke, 2007), materials (Ludwig et al., 2006; Abidian and Martin, 2008), approaches to mitigate chronic reactive tissue responses (Shain et al., 2003; Spataro et al., 2005), and minimally damaging insertion techniques (Bjornsson et al., 2006; Johnson et al., 2007) are being investigated to create longerlasting interfaces for high-fidelity recording and stimulation. The engineering strategy is to use these and related advances to develop a design space to systematically result in progressively better implantable devices for chronic neural interfaces (e.g., consistent and measurable performance improvements with successive device versions). This rational design of neural interfaces requires standard protocols and performance assessments that are currently being developed.

\section{Large-scale recording of neuronal and field activity}

Studying neurons and neuronal pools requires simultaneous monitoring of the activity of large numbers of individual neurons in multiple brain regions. A major goal therefore is to record from statistically representative samples of identified neurons from several local areas while minimally interfering with brain activity. The technical challenge is to position individual or small sets of recording sites sufficiently close (typically tens to several hundred micrometers) to the target neurons or neuronal segments. Advances in microelectrode technologies increase the numbers and precise positioning of electrode sites, and thus, enable progressively more powerful experimental approaches to understanding the interaction of neurons and neuronal pools.

This type of large-scale recording of neuronal activity involves three critical components: (1) spike sorting methods, (2) identification of neuronal types, and (3) characterization of synaptic inputs. Currently, wires and microfabricated silicon electrode arrays can record from large numbers of neurons and monitor local neural circuits at work (Fig. 1E) (McNaughton et al., 1983; Hoffman and McNaughton, 2002; Csicsvari et al., 2003; Barthó et al., 2004; Buzsáki, 2004).

Isolation and identification of neurons by extracellular signatures An indispensable step in spike train analysis is the isolation of single neurons on the basis of features in extracellular recordings. Spike sorting methods fall into two broad classes. The first class attempts to separate spikes on the basis of amplitude and waveform variation; the second method separates units on the basis of their spatial location (Wilson and McNaughton, 1993; Buzsáki, 2004). Unfortunately, none of these methods is uniformly satisfactory. When neurons are strongly activated, their amplitude, rise time, decay time and spike width change as a function of the membrane potential before the spike and as a function of the immediate firing history of the neurons. The spike amplitude variation is most substantial during complex spike burst production, with as much as $80 \%$ amplitude reduction, primarily because of $\mathrm{Na}^{+}$channel inactivation (Harris et al., 2001). Therefore, amplitude and waveform-based classification programs will separate action potentials from a single neuron as if they were emitted by many. The amplitude and waveform variability of the extracellularly recorded spike is the major cause of unit isolation errors (Harris et al., 2000; Henze et al., 2000). Additionally, in long-term chronic recordings using implantable microelectrode arrays, unit isolation issues are typically, but not always, compounded by a progressive degradation in signal quality (e.g., ratio of spike amplitude to background noise) for implant lifetimes more than several months.

The spatial triangulation approach is based on the tacit assumption that the extracellularly recorded spikes emanate from point sources (McNaughton et al., 1983). However, every part of the neuronal membrane is capable of generating action potentials and what is observed in the extracellular space is a result of the complex geometry of neurons and the propagation of spike within the neuron. The extent of the somatodendritic backpropagation of the action potential varies as a function of the excitatory and inhibitory inputs impinging on the neuron and the state of various other conductances. The spike recorded in the extracellular field is a summation of the integrated signals from both soma and large proximal dendrites. Thus, the extent of somatodendritic spike backpropagation can affect the estimation of the neuron's virtual "point source" location and may place the same neuron at different locations, resulting in omission errors of unit isolation (Harris et al., 2000). A further problem with the pointsource assumption for action potentials is that the somatic origin is not always resolvable with distant recording sites. For example, in the rat neocortex, extracellular spikes can be recorded from the apical shaft of layer $\mathrm{V}$ pyramidal neurons as far as $500 \mu \mathrm{m}$ from the cell body (Buzsáki and Kandel, 1998). As a consequence, electrodes placed, for example, in layer IV, can equally record from layer IV cell bodies or apical dendrites of deeper neurons. Large neurons in the primate cortex are especially prone to such misclassification errors because their spikes can be recorded several hundred micrometers from the cell bodies.

To a large extent, these sources of unit separation errors can be reduced by recording at multiple sites parallel with the axodendritic axis of the neurons. This can be achieved, for example, by using a silicon probe with a shank positioned along the axodendritic axis and with small electrode sites precisely clustered along the shank.

\section{Classification of neuron types}

Isolated single units need to be classified into known cell groups of the cortex. This is a very important requirement because cortical networks consist of several neuronal classes, each with a specific computation task (Freund and Buzsáki, 1996; Klausberger and Somogyi, 2008). The potential conclusion from an experiment reporting that all cortical pyramidal cells did one thing and all interneurons something else is qualitatively different from the conclusion that can be drawn from the information that $80 \%$ of all (unclassified) cells behaved differently from the rest.

Unfortunately, current knowledge about the extracellular features of neurons in the neocortex severely limits the reliable separation of principal cells of different layers and the numerous interneuron classes. Spike duration criterion has been used to distinguish fast spiking interneurons from pyramidal cells in the rodent cortex (Mitchell et al., 2007). Simultaneous recording of local neuron pairs can provide physiological clues about the excitatory or inhibitory nature of the recorded units because their cross-correlation can display robust, short-time-scale correlations, indicative of monosynaptic excitatory or inhibitory connections (Fig. $1 F$ ). Because such synaptically connected pairs are rare (Barthó et al., 2004; Fujisawa et al., 2008), large-scale recording of neuronal populations is needed for their identification.

\section{Characterization of synaptic inputs}

A necessary requirement for a more complete understanding of the transformation of inputs by a neuron or neuronal assemblies 
is information about both their input and output. Unfortunately, no method is available for monitoring all inputs at the resolution of dendrites and spines of single neurons. However, membrane currents generated by neurons pass through the extracellular space. These currents can be measured by electrodes placed outside the neurons. The field potential (i. e., local mean field), recorded at any given site, reflects the linear sum of numerous overlapping fields generated by current sources (current from the intracellular space to the extracellular space) and sinks (current from the extracellular space to the intracellular space) distributed along multiple cells. Local field potential measurements combined with recording of neuronal discharges is the best experimental tool available to study the influence of cytoarchitectural properties, such as cortical lamination, distribution, size, and network connectivity of neural elements on electrogenesis. However, large number of observation points combined with decreased distance between the recording sites are required for high spatial resolution and for making interpretation of the underlying cellular events possible. Recording the voltage gradients by geometrically arranged sites of silicon probes within a target allow current densities to be calculated for an estimation of the mean input to the neuron group in the recorded volume (Nadasdy et al., 1998).

Large-scale recording of neuronal and field activity is continuing to improve through systematic advances in the underlying neural interface technologies that provide the ability to tune electrode arrays to better match neuron morphologies and distributions in the targeted volume and to have optimized signal recording characteristics. This involves engineering details such as smaller feature sizes to support higher site density and more precise site layouts. It also involves high-level aspects such as packaging and quality control to support more component-level integration in a cost-effective manner. This expanded design space is illustrated in a next-generation three-dimensional microelectrode array that provides a modular and customizable way to integrate several one- or two-dimensional planar probes into a three-dimensional assembly to more precisely and fully access a target volume (Fig. 1C). With more device complexity and increased numbers of sites, getting signals from or to the microelectrodes becomes a significant issue, especially in awake and behaving preparations and brain-computer applications. Although physical connectors are the current de facto standard, there is notable progress in developing low-power, low-noise electronic interfaces with wireless interfaces (Neihart and Harrison, 2005; Song et al., 2005, 2007; Oweiss, 2006; Ghovanloo and Najafi, 2007; Sodagar et al., 2007; Lee et al., 2008).

\section{Engaging the brain: recurrent brain-computer interfaces}

Brain-computer interface (BCI) studies are providing new insights into accessing cortical circuits through chronic, implantable neural interfaces and engaging them in various types of realtime, closed-loop experimental paradigms. Most BCI systems typically allow neural activity to control computer cursors or external devices (Wolpaw et al., 2002; Carmena et al., 2003; Hochberg et al., 2006; Velliste et al., 2008). Recently, the BCI concept was extended to create a recurrent BCI (R-BCI) system in which neural activity is recorded and processed in real time to control electrical stimulation of particular areas of the brain or muscles through implanted electrodes. Such R-BCIs implement an artificial connection that the adaptive brain could learn to incorporate into normal function. This autonomous recurrent BCI paradigm opens new experimental directions and has promise for several clinical applications. R-BCI systems are intricately related to neural interface technologies because system performance depends not only on neural processing, but also on the performance of the two separate (recording and stimulation) interfaces and the embedded real-time computational unit.

Initial R-BCIs were developed using a "Neurochip" containing autonomously operating circuitry that interacts continuously with the brain of a monkey. The system consisted of a printed circuit board populated with off-the-shelf components and connected to wire electrodes that record the activity of motor cortex cells and/or muscles (Mavoori et al., 2005; Jackson et al., 2006b). The amplified activity was digitized and processed by a programmable computer chip and stored to on-board memory and/or converted in real time to deliver activity-contingent electrical stimuli back to the cortex (Fig. $2 A, B$ ). Chronic implantation of the battery-powered Neurochip on the skull allowed continuous operation during free behavior and sleep (Jackson et al., 2007).

\section{Artificial recurrent feedback connections}

Clinically, R-BCIs could bridge impaired biological connections and allow the subject to learn to control this prosthetic connection to compensate for lost pathways (Jackson et al., 2006b). Current experiments are testing the ability of nonhuman primates to use motor cortical cell activity to control functional electrical stimulation (FES) of paralyzed muscles (Moritz et al., 2008). In these experiments, recurrent connections, largely via rack-mounted instrumentation, were used to implement direct control of muscle FES during peripheral nerve block. The monkeys' accuracy in using the R-BCI to acquire torque targets improved with practice. Bidirectional movements via independent FES of antagonist muscle groups were controlled by either high and low firing rates of single cells or by modulating pairs of cells with each neuron controlling stimulation of a different muscle group. Surprisingly, neurons could control goal-directed FES equally well regardless of whether they were originally modulated with movement, thus demonstrating an increased source of control signals for brain-computer interfaces. These results demonstrate that direct artificial connections between single cortical cells and muscles can be used to compensate for interrupted physiological pathways and restore volitional goal-directed control of movement to paralyzed limbs. The degree to which prolonged implementation of these artificial connections will allow the brain to integrate them into normal movements remains to be tested.

\section{Long-term modification of synaptic connections through} Hebbian mechanisms

By delivering stimuli synchronized with cell activity, continuous operation of the R-BCI has produced significant long-lasting changes in neural connections in motor cortex (Jackson et al., 2006a). The Neurochip converted the action potentials of a single motor cortex neuron to stimuli delivered within a few milliseconds to a neighboring cortical site. Operating continuously during $24 \mathrm{~h}$ of free behavior and sleep, this conditioning regimen led to subsequent long-lasting changes in the movement evoked from repetitive microstimulation of the recording site, bringing its output closer to the movements evoked from the stimulation site (Fig. 2C). The simplest mechanism mediating this change is Hebbian strengthening of the physiological connections from the recording site to the synchronously stimulated site. Remarkably, the changes in cortical output remained stable for at least $10 \mathrm{~d}$ after the end of conditioning, indicating a potent long-lasting effect. This R-BCI-induced plasticity opens opportunities for many basic experiments into the underlying mechanisms and replication at other sites. The paradigm also has potential therapeutic application to strengthen weak biological connections. For 

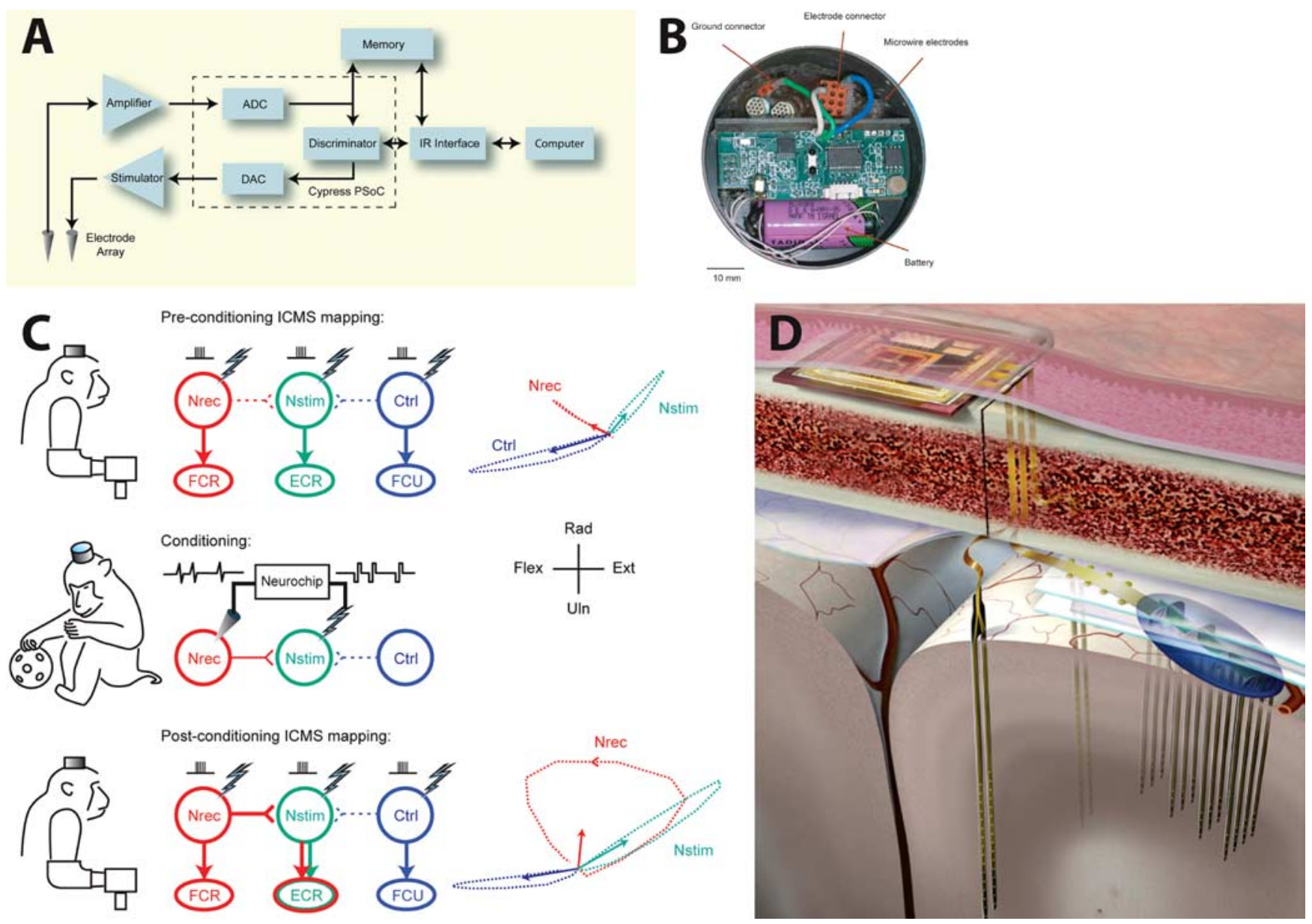

Figure 2. A, Schematic of signal flow in R-BCI (Mavoori et al., 2005). B, Neurochip circuit board, electrode connector, and battery in circular chamber implanted on monkey's head [Jackson et al., (2007), their Fig. 1A]. C, Continuous operation of a cortical recurrent BCI leads to long-lasting changes in physiological connections. Top, Intracranial microstimulation at three different motor cortex sites with the monkey at rest evoked three different muscle responses (center) and different isometric torques about the wrist (right). Arrows at right indicate means of $200 \mathrm{~ms}$ torque trajectories. Middle, Conditioning involved $2 \mathrm{~d}$ of triggering microstimuli at site Nstim for every spike recorded at Nrec during free behavior and sleep. Bottom, After conditioning, the output effects evoked from site Nrec had changed to include those from Nstim, an effect that lasted beyond a week [Jackson et al. (2006a), their Figs. 2, 5]. D, Illustration of a proposed fully implantable integrated microsystem (University of Michigan).

example, activity-dependent cortical stimulation could facilitate recovery from stroke or traumatic brain injury.

The R-BCI paradigm has numerous possible applications, depending on the input signals [neuronal action potentials, field potentials, electrocorticographic (ECoG), or EMG], and the output sites (cortex, spinal cord, cerebellum, muscles, or reinforcement sites), and the transform between them (direct conversion to proportional stimulation, computed functions of detected activity, simulated neural networks). Ultimately, successful incorporation of these R-BCIs into brain function will depend on the brain's ability to exploit and adapt to consistent contingencies. Looking ahead, the possibility of transforming spatiotemporal patterns of multichannel neural recordings to patterns of multichannel stimulation may make it possible to implement recurrent computations in higherorder cognitive areas of the brain, like hippocampus, conceivably producing a "cognitive prosthesis" (Berger and Glanzmann, 2005; Berger et al., 2005).

Further developments in implantable neural interface technologies will enable more sophisticated R-BCIs through largerscale, higher-fidelity, and longer-lasting microelectrode arrays. Additionally, sophisticated, low-power integrated circuits for signal conditioning and embedded computing and better packaging systems for implantable electronics will drive the development of next-generation implantable integrated microsystems that have increased real-time computing power (Fig. 2D).

\section{Translating microscale neural interface technologies for clinical use}

Although there are significant research applications for advanced neural interface technologies, the ultimate application of these technologies is in understanding human nervous system function and in restoring lost function to patients. Neural interface technology has been applied to humans mainly on the input side, with electrical stimulation of the spinal cord and brain being practiced for nearly four decades. Since the first descriptions of implantable neurostimulators in the 1950s and 1960s (Shealy et al., 1967), neural interface systems have steadily become more sophisticated and more robust. However, the translation of research-grade devices to clinical-grade devices takes a significant engineering development effort to make the devices and their components amenable for use in the rugged neurosurgical environment and safe and effective in their intended application.

Significant technical issues can be expected with any device designed to withstand the harsh environment of the human body for years. Failure rates for implantable stimulation devices can 


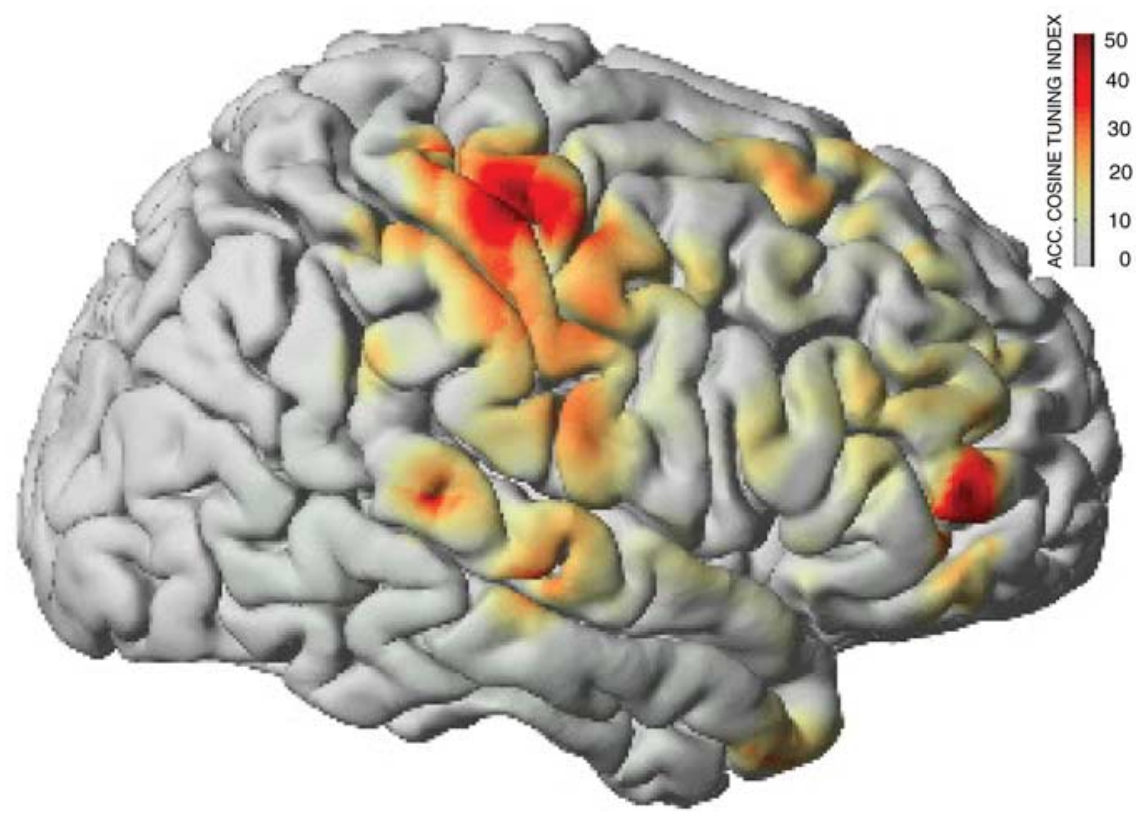

Figure 3. Brain activity captured by ECoG signals during a hand movement task in five human subjects. Color-coded shading (see color bar) illustrates as an average over all subjects how much information about movement direction is encoded by ECOG signals in different cortical areas. Most of that information is captured by hand representations of motor cortex. This figure was modified with permission from Schalk et al. (2007b) IOP Publishing, their Figure 5a. See Schalk et al. (2007b) for methodological details.

exceed 40\% (Rosenow et al., 2006). Engineering analysis of mechanical failures of these devices can provide insights to appropriate surgical techniques to minimize mechanical stresses and strains on the system (Henderson et al., 2006).

Recently, cortical neural interfacing with microscale devices has been demonstrated in humans (Hochberg et al., 2006). Although it represents a remarkable achievement, this system is at a stage similar to the first spinal cord stimulator systems, using percutaneous connectors with all of their disadvantages including infection risks, susceptibility to damage, etc. Next-generation microscale neural interface systems will need to approach the safety, durability, and ease of use of current clinical systems such as those used for deep brain stimulation (DBS), including wireless interfaces.

DBS has become a standard treatment for Parkinson's disease, with good results over many years (Krack et al., 2003). The interface to the brain, relatively large compared with microelectrode arrays, consists of a 1.27-mm-diameter probe with four cylindrical contacts $1.5 \mathrm{~mm}$ in length, spaced $0.5 \mathrm{~mm}$ apart. The electrode contacts are attached via robust coiled wire extensions to a titanium-encased pulse generator implanted in the chest. Another system consists of similar electrodes but with the pulse generator implanted in the skull (Fountas et al., 2005). Both designs have proven to be robust in clinical practice, with the latter system incorporating both sensing and stimulation capabilities.

It is thus technically feasible to create clinically useful interfaces that can sense and stimulate both the cortical surface and deep nuclei. New systems must take into account the challenges of the operating room environment. Implantable devices must be robust enough to allow rough handling by neurosurgeons. Time is of the essence in the operating room, so delivery systems must be simple and quickly deployable. Connectors should be reliable, fluid-proof, and as small as possible, a challenge when the number of connections potentially reaches into the hundreds. Fully developed systems for human use will require not only well en- gineered devices, but also carefully developed plans for packaging and delivery.

The microscale cortical recording array used in the Cyberkinetics human trial (Hochberg et al., 2006) provides an example of how next-generation packaging and delivery could promote more widespread adoption. This device has been implanted with good success using a wide cortical exposure via craniotomy. By engineering a delivery system that eliminates the need for extensive visualization, these arrays could be implanted in a minimally invasive manner similar to that used for DBS. This could, for example, take the form of a prepackaged "cartridge" with the pneumatic inserter attached, incorporating a pressure sensor that allows for precise positioning on the cortex and even possibly automated insertion. Such a system would allow easy implantation with a high degree of reproducibility.

\section{Recordings from the surface of the brain} Invasive BCIs with implanted intracortical microelectrode arrays use local activity from neurons recorded within the brain (Georgopoulos et al., 1986; Serruya et al., 2002; Taylor et al., 2002; Shenoy et al., 2003; Andersen et al., 2004; Musallam et al., 2004; Lebedev et al., 2005; Hochberg et al., 2006; Santhanam et al., 2006; Lee et al., 2008; Velliste et al., 2008). Signals recorded within cortex have high fidelity, but the stability of intracortical recordings can be variable and decays with time (Santhanam et al., 2007).

Noninvasive BCIs use electroencephalographic (EEG) activity recorded from the scalp (Farwell and Donchin, 1988; Wolpaw et al., 1991; Sutter, 1992; McFarland et al., 1993, 2008; Pfurtscheller et al., 1993, 2000; Wolpaw and McFarland, 1994, 2004; Birbaumer et al., 1999; Millán et al., 2004; Kübler et al., 2005; Blankertz et al., 2006; Vaughan et al., 2006; Müller et al., 2008). Although EEG-based BCIs support higher performance than often assumed, the acquisition of high levels of brain-based control typically requires extensive user training, and BCI performance can also be variable. Despite recent encouraging evidence that BCI technologies using noninvasive or intracortical methods can be useful to people with paralysis [Kübler et al. (2005) and Hochberg et al. (2006), respectively], the difficulties described above currently impede widespread clinical implementation of BCI technologies (Schalk, 2008). ECoG recordings from the surface of the brain may combine the advantages of noninvasive and intracortical BCI approaches, and may provide the basis for powerful but yet practical BCI systems for the disabled.

\section{ECoG signals}

It has long been known that ECoG signals recorded from the surface of the brain also hold information about movements, and that this information could be used for device control (Brindley and Craggs, 1972; Craggs, 1975). It has dramatically higher spatial resolution than EEG [i.e., tenths of millimeters vs centimeters (Freeman et al., 2003)], broader bandwidth (Staba et al., 2002), higher characteristic amplitude, and far less vulnerability to artifacts such as EMG (Freeman et al., 2003). At the same time, because ECoG does not require penetration of the cortex, it may 
have greater long-term stability than intracortical recordings (Loeb et al., 1977; Bullara et al., 1979; Yuen et al., 1987; Margalit et al., 2003).

\section{Signal fidelity of ECoG}

Initial evidence in animals (Mehring et al., 2003; Rickert et al., 2005) and more recent evidence from humans (Leuthardt et al., 2004; Schalk et al., 2007b) demonstrate that ECoG can give detailed information about kinematic parameters of hand movements (Fig. 3). Moreover, the fidelity of that information, i.e., the correlation between actual and decoded position/velocity of hand movements in humans, was shown to be within the range of the results that were previously reported for intracortical microelectrode recordings in nonhuman primates [see Schalk et al. (2007b), their Table 3]. These human results have since been replicated and further extended for decoding of arm movements (Pistohl et al., 2008; Sanchez et al., 2008), flexion of individual fingers (Kubanek et al., 2007), and even specific aspects (such as the type of phoneme) of actual or imagined speech (Schalk et al., 2007a). Finally, several studies demonstrated that it is possible to combine general understanding of motor-related ECoG responses (Crone et al., 1998a,b; Aoki et al., 1999; Graimann et al., 2002; Sinai et al., 2005; Leuthardt et al., 2007; Miller et al., 2007) with the more specific understanding described above to implement different ECoG-based BCIs (Leuthardt et al., 2004; Wilson et al., 2006; Felton et al., 2007; Schalk et al., 2008) in humans using the BCI2000 software framework (Schalk et al., 2004). These studies showed that ECoG supports accurate nonmuscular one- or two-dimensional movement control in humans with little subject training.

\section{Summary}

Advances in neural interface technologies intersect with increasingly sophisticated experimental approaches to create innovative approaches for investigating and engaging the brain. The accessible design space for neural interfaces is becoming sufficiently developed to enable enhanced devices that are tuned to meet aggressive application requirements. In the next 3-5 years, there is potential for significant progress along the emerging roadmap for neural interface technologies. Continued application-driven advances will increase the selectivity, sensitivity, precision, bandwidth, reliability, and functional lifetimes of implantable microelectrode arrays for neural recording and stimulation. Focused investigations will increase understanding and control of reactive tissue responses to chronically implanted neural interface devices. Interdisciplinary, engineering science developments will open up ways to integrate implantable microelectrode technologies with complementary types of neural interface technologies, including chemical sensing, drug delivery, optical imaging, and genetic manipulations. Development of standards in the design, assessment, and use of implantable neural interface devices will increase the pace of development and the effectiveness of the technologies and devices. And, there will be additional efforts to translate research-grade microscale neural interface devices to clinical devices for diagnostic and therapeutic applications.

The stage is set for increased interdisciplinary collaboration to drive creative interactions among neuroscience, neural interface technology, and clinical applications. The synergy created by these activities will push progress to new heights and usher in the realization of robust implantable devices for long-term study and treatment of the CNS.

\section{References}

Abidian MR, Martin DC (2008) Experimental and theoretical characterization of implantable neural microelectrodes modified with conducting polymer nanotubes. Biomaterials 29:1273-1283.

Andersen RA, Burdick JW, Musallam S, Pesaran B, Cham JG (2004) Cognitive neural prosthetics. Trends Cogn Sci 8:486-493.

Aoki F, Fetz EE, Shupe L, Lettich E, Ojemann GA (1999) Increased gammarange activity in human sensorimotor cortex during performance of visuomotor tasks. Clin Neurophysiol 110:524-537.

Bartels J, Andreasen D, Ehirim P, Mao H, Seibert S, Wright EJ, Kennedy P (2008) Neurotrophic electrode: method of assembly and implantation into human motor speech cortex. J Neurosci Methods 174:168-176.

Barthó P, Hirase H, Monconduit L, Zugaro M, Harris KD, Buzsáki G (2004) Characterization of neocortical principal cells and interneurons by network interactions and extracellular features. J Neurophysiol 92:600-608.

Berger T, Glanzmann DL (2005) Toward replacement parts for the brain. Cambridge, MA: MIT.

Berger TW, Ahuja A, Courellis SH, Deadwyler SA, Erinjippurath G, Gerhardt GA, Gholmieh G, Granacki JJ, Hampson R, Hsaio MC, LaCoss J, Marmarelis VZ, Nasiatka P, Srinivasan V, Song D, Tanguay AR, Wills J (2005) Restoring lost cognitive function. IEEE Eng Med Biol Mag 24:30-44.

Birbaumer N, Ghanayim N, Hinterberger T, Iversen I, Kotchoubey B, Kübler A, Perelmouter J, Taub E, Flor H (1999) A spelling device for the paralysed. Nature 398:297-298.

Bjornsson CS, Oh SJ, Al-Kofahi YA, Lim YJ, Smith KL, Turner JN, De S, Roysam B, Shain W, Kim SJ (2006) Effects of insertion conditions on tissue strain and vascular damage during neuroprosthetic device insertion. J Neural Eng 3:196-207.

Blankertz B, Dornhege G, Krauledat M, Müller KR, Kunzmann V, Losch F, Curio G (2006) The Berlin brain-computer interface: EEG-based communication without subject training. IEEE Trans Neural Syst Rehabil Eng 14:147-152.

Brindley GS, Craggs MD (1972) The electrical activity in the motor cortex that accompanies voluntary movement. J Physiol 223:28P-29P.

Bullara LA, Agnew WF, Yuen TG, Jacques S, Pudenz RH (1979) Evaluation of electrode array material for neural prostheses. Neurosurgery 5:681-686.

Buzsáki G (2004) Large-scale recording of neuronal ensembles. Nat Neurosci 7:446-451.

Buzsáki G, Kandel A (1998) Somadendritic backpropagation of action potentials in cortical pyramidal cells of the awake rat. J Neurophysiol 79:1587-1591.

Carmena JM, Lebedev MA, Crist RE, O'Doherty JE, Santucci DM, Dimitrov DF, Patil PG, Henriquez CS, Nicolelis MA (2003) Learning to control a brain-machine interface for reaching and grasping by primates. PLoS Biol 1:E42.

Craggs MD (1975) Cortical control of motor prostheses: using the cordtransected baboon as the primate model for human paraplegia. Adv Neurol 10:91-101.

Crone NE, Miglioretti DL, Gordon B, Sieracki JM, Wilson MT, Uematsu S, Lesser RP (1998a) Functional mapping of human sensorimotor cortex with electrocorticographic spectral analysis. I. Alpha and beta eventrelated desynchronization. Brain 121:2271-2299.

Crone NE, Miglioretti DL, Gordon B, Lesser RP (1998b) Functional mapping of human sensorimotor cortex with electrocorticographic spectral analysis. II. Event-related synchronization in the gamma band. Brain 121:2301-2315.

Csicsvari J, Henze DA, Jamieson B, Harris KD, Sirota A, Barthó P, Wise KD, Buzsáki G (2003) Massively parallel recording of unit and local field potentials with silicon-based electrodes. J Neurophysiol 90:1314-1323.

Farwell LA, Donchin E (1988) Talking off the top of your head: toward a mental prosthesis utilizing event-related brain potentials. Electroencephalogr Clin Neurophysiol 70:510-523.

Felton EA, Wilson JA, Williams JC, Garell PC (2007) Electrocorticographically controlled brain-computer interfaces using motor and sensory imagery in patients with temporary subdural electrode implants. Report of four cases. J Neurosurg 106:495-500.

Fountas KN, Smith JR, Murro AM, Politsky J, Park YD, Jenkins PD (2005) Implantation of a closed-loop stimulation in the management of medically refractory epilepsy. Stereotact Funct Neurosurg 83:153-158.

Freeman WJ, Holmes MD, Burke BC, Vanhatalo S (2003) Spatial spectra of 
scalp EEG and EMG from awake humans. Clin Neurophysiol 114:1053-1068.

Freund TF, Buzsáki G (1996) Interneurons of the hippocampus. Hippocampus 6:347-470.

Fujisawa S, Amarasingham A, Harrison MT, Buzsáki G (2008) Behavdependent short-term assembly dynamics in the medial prefrontal cortex. Nat Neurosci 11:823-833.

Georgopoulos AP, Schwartz AB, Kettner RE (1986) Neuronal population coding of movement direction. Science 233:1416-1419.

Ghovanloo M, Najafi K (2007) A wireless implantable multichannel microstimulating system-on-a-chip with modular architecture. IEEE Trans Neural Syst Rehabil Eng 15:449-457.

Graimann B, Huggins JE, Levine SP, Pfurtscheller G (2002) Visualization of significant ERD/ERS patterns in multichannel EEG and ECoG data. Clin Neurophysiol 113:43-47.

Harris KD, Henze DA, Csicsvari J, Hirase H, Buzsáki G (2000) Accuracy of tetrode spike separation as determined by simultaneous intracellular and extracellular measurements. J Neurophysiol 84:401-414.

Harris KD, Hirase H, Leinekugel X, Henze DA, Buzsáki G (2001) Temporal interaction between single spikes and complex spike bursts in hippocampal pyramidal cells. Neuron 32:141-149.

Henderson JM, Schade CM, Sasaki J, Caraway DL, Oakley JC (2006) Prevention of mechanical failures in implanted spinal cord stimulation systems. Neuromodulation 9:183-191.

Henze DA, Borhegyi Z, Csicsvari J, Mamiya A, Harris KD, Buzsáki G (2000) Intracellular features predicted by extracellular recordings in the hippocampus in vivo. J Neurophysiol 84:390-400.

Hetke JF, Anderson DJ (2002) Silicon microelectrodes for extracellular recording. In: Handbook of neuroprosthetic methods (Finn WE, LoPresti PG, eds). Boca Raton, FL: CRC.

Hochberg LR, Serruya MD, Friehs GM, Mukand JA, Saleh M, Caplan AH, Branner A, Chen D, Penn RD, Donoghue JP (2006) Neuronal ensemble control of prosthetic devices by a human with tetraplegia [see comment]. Nature 442:164-171.

Hoffman KL, McNaughton BL (2002) Coordinated reactivation of distributed memory traces in primate neocortex. Science 297:2070-2073.

Jackson A, Fetz EE (2007) Compact movable microwire array for long-term chronic unit recording in cerebral cortex of primates. J Neurophysiol 98:3109-3118.

Jackson A, Mavoori J, Fetz EE (2006a) Long-term motor cortex plasticity induced by an electronic neural implant. Nature 444:56-60.

Jackson A, Moritz CT, Mavoori J, Lucas TH, Fetz EE (2006b) The Neurochip BCI: towards a neural prosthesis for upper limb function. IEEE Trans Neural Syst Rehabil Eng 14:187-190.

Jackson A, Mavoori J, Fetz EE (2007) Correlations between the same motor cortex cells and arm muscles during a trained task, free behavior, and natural sleep in the macaque monkey. J Neurophysiol 97:360-374.

Johnson MD, Kao OE, Kipke DR (2007) Spatiotemporal pH dynamics following insertion of neural microelectrode arrays. J Neurosci Methods 160:276-287.

Kipke DR, Vetter RJ, Williams JC, Hetke JF (2003) Silicon-substrate intracortical microelectrode arrays for long-term recording of neuronal spike activity in cerebral cortex. IEEE Trans Neural Syst Rehabil Eng 11:151-155.

Klausberger T, Somogyi P (2008) Neuronal diversity and temporal dynamics: the unity of hippocampal circuit operations. Science 321:53-57.

Krack P, Batir A, Van Blercom N, Chabardes S, Fraix V, Ardouin C, Koudsie A, Limousin PD, Benazzouz A, LeBas JF, Benabid AL, Pollak P (2003) Five-year follow-up of bilateral stimulation of the subthalamic nucleus in advanced Parkinson's disease. N Engl J Med 349:1925-1934.

Kubanek J, Miller K, Ojemann J, Wolpaw JR, Schalk G (2007) Decoding finger movements from electrocorticographic signals (ECoG) in humans. Soc Neurosci Abstr 33:414.10.

Kübler A, Nijboer F, Mellinger J, Vaughan TM, Pawelzik H, Schalk G, McFarland DJ, Birbaumer N, Wolpaw JR (2005) Patients with ALS can use sensorimotor rhythms to operate a brain-computer interface. Neurology 64:1775-1777.

Lebedev MA, Carmena JM, O'Doherty JE, Zacksenhouse M, Henriquez CS, Principe JC, Nicolelis MA (2005) Cortical ensemble adaptation to represent velocity of an artificial actuator controlled by a brain-machine interface. J Neurosci 25:4681-4693.

Lee J, Rhew H-G, Kipke DR, Flynn M (2008) A 64-channel programmable closed-loop deep brain stimulator with 8-channel neural amplifier and logarithmic ADC. Paper presented at 2008 IEEE Symposium on VLSI Circuits, Honolulu, HI, June.

Leuthardt EC, Schalk G, Wolpaw JR, Ojemann JG, Moran DW (2004) A brain-computer interface using electrocorticographic signals in humans. J Neural Eng 1:63-71.

Leuthardt EC, Miller K, Anderson NR, Schalk G, Dowling J, Miller J, Moran DW, Ojemann JG (2007) Electrocorticographic frequency alteration mapping: a clinical technique for mapping the motor cortex. Neurosurgery 60:260-270; discussion 270-271.

Liu X, McCreery DB, Carter RR, Bullara LA, Yuen TG, Agnew WF (1999) Stability of the interface between neural tissue and chronically implanted intracortical microelectrodes. IEEE Trans Rehabil Eng 7:315-326.

Loeb GE, Walker AE, Uematsu S, Konigsmark BW (1977) Histological reaction to various conductive and dielectric films chronically implanted in the subdural space. J Biomed Mater Res 11:195-210.

Ludwig KA, Uram JD, Yang J, Martin DC, Kipke DR (2006) Chronic neural recordings using silicon microelectrode arrays electrochemically deposited with a poly(3,4-ethylenedioxythiophene) (PEDOT) film. J Neural Eng 3:59-70.

Margalit E, Weiland JD, Clatterbuck RE, Fujii GY, Maia M, Tameesh M, Torres G, D’Anna SA, Desai S, Piyathaisere DV, Olivi A, de Juan E Jr, Humayun MS (2003) Visual and electrical evoked response recorded from subdural electrodes implanted above the visual cortex in normal dogs under two methods of anesthesia. J Neurosci Methods 123:129-137.

Mavoori J, Jackson A, Diorio C, Fetz E (2005) An autonomous implantable computer for neural recording and stimulation in unrestrained primates. J Neurosci Methods 148:71-77.

McCreery D, Pikov V, Lossinsky A, Bullara L, Agnew W (2004) Arrays for functional microstimulation of the lumbosacral spinal cord. IEEE Trans Neural Syst Rehabil Eng 12:195-207.

McCreery D, Lossinsky A, Pikov V, Liu X (2006) Microelectrode array for chronic deep-brain microstimulation and recording. IEEE Trans Biomed Eng 53:726-737.

McFarland DJ, Neat GW, Wolpaw JR (1993) An EEG-based method for graded cursor control. Psychobiology 21:77-81.

McFarland DJ, Krusienski DJ, Sarnacki WA, Wolpaw JR (2008) Emulation of computer mouse control with a noninvasive brain-computer interface. J Neural Eng 5:101-110.

McNaughton BL, O’Keefe J, Barnes CA (1983) The stereotrode: a new technique for simultaneous isolation of several single units in the central nervous system from multiple unit records. J Neurosci Methods 8:391-397.

Mehring C, Rickert J, Vaadia E, Cardosa de Oliveira S, Aertsen A, Rotter S (2003) Inference of hand movements from local field potentials in monkey motor cortex. Nat Neurosci 6:1253-1254.

Millán JdR, Renkens F, Mouriño J, Gerstner W (2004) Noninvasive brainactuated control of a mobile robot by human EEG. IEEE Trans Biomed Eng 51:1026-1033.

Miller KJ, Leuthardt EC, Schalk G, Rao RP, Anderson NR, Moran DW, Miller JW, Ojemann JG (2007) Spectral changes in cortical surface potentials during motor movement. J Neurosci 27:2424-2432.

Mitchell JF, Sundberg KA, Reynolds JH (2007) Differential attentiondependent response modulation across cell classes in macaque visual area V4. Neuron 55:131-141.

Moritz CT, Perlmutter SI, Fetz EE (2008) Monkeys use cortical activity to control functional electrical stimulation of paralyzed muscles. Soc Neurosci Abstr 34:779.19.

Motta PS, Judy JW (2005) Multielectrode microprobes for deep-brain stimulation fabricated with a customizable 3-D electroplating process. IEEE Trans Biomed Eng 52:923-933.

Müller KR, Tangermann M, Dornhege G, Krauledat M, Curio G, Blankertz B (2008) Machine learning for real-time single-trial EEG-analysis: from brain-computer interfacing to mental state monitoring. J Neurosci Methods 167:82-90.

Musallam S, Corneil BD, Greger B, Scherberger H, Andersen RA (2004) Cognitive control signals for neural prosthetics. Science 305:258-262.

Musallam S, Bak MJ, Troyk PR, Andersen RA (2007) A floating metal microelectrode array for chronic implantation. J Neurosci Methods 160:122-127.

Nadasdy Z, Csicsvari J, Penttonen M, Buzsáki G (1998) Extracellular recording and analysis of electrical activity: from single cells to ensembles. 
In: Neuronal ensembles: strategies for recording and decoding, Ed 1 (Eichenbaum H, Davis JL, eds), pp 17-55. New York: Wiley.

Neihart NM, Harrison RR (2005) Micropower circuits for bidirectional wireless telemetry in neural recording applications. IEEE Trans Biomed Eng 52:1950-1959.

Neves HP, Ruther P (2007) The NeuroProbes Project. Conf Proc IEEE Eng Med Biol Soc 2007:6443-6445.

Nicolelis MA, Dimitrov D, Carmena JM, Crist R, Lehew G, Kralik JD, Wise SP (2003) Chronic, multisite, multielectrode recordings in macaque monkeys. Proc Natl Acad Sci U S A 100:11041-11046.

Nordhausen CT, Maynard EM, Normann RA (1996) Single unit recording capabilities of a 100 microelectrode array. Brain Res 726:129-140.

Oweiss KG (2006) A systems approach for data compression and latency reduction in cortically controlled brain machine interfaces. IEEE Trans Biomed Eng 53:1364-1377.

Pfurtscheller G, Flotzinger D, Kalcher J (1993) Brain-computer interface-a new communication device for handicapped persons. J Microcomp App 16:293-299.

Pfurtscheller G, Neuper C, Guger C, Harkam W, Ramoser H, Schlögl A, Obermaier B, Pregenzer M (2000) Current trends in Graz braincomputer interface (BCI) research. IEEE Trans Rehabil Eng 8:216-219.

Pistohl T, Ball T, Schulze-Bonhage A, Aertsen A, Mehring C (2008) Prediction of arm movement trajectories from ECoG-recordings in humans. J Neurosci Methods 167:105-114.

Rennaker RL, Ruyle AM, Street SE, Sloan AM (2005) An economical multichannel cortical electrode array for extended periods of recording during behavior. J Neurosci Methods 142:97-105.

Rickert J, Oliveira SC, Vaadia E, Aertsen A, Rotter S, Mehring C (2005) Encoding of movement direction in different frequency ranges of motor cortical local field potentials. J Neurosci 25:8815-8824.

Rosenow JM, Stanton-Hicks M, Rezai AR, Henderson JM (2006) Failure modes of spinal cord stimulation hardware. J Neurosurg Spine 5:183-190.

Rousche PJ, Normann RA (1998) Chronic recording capability of the Utah Intracortical Electrode Array in cat sensory cortex. J Neurosci Methods 82:1-15.

Sanchez JC, Gunduz A, Carney PR, Principe JC (2008) Extraction and localization of mesoscopic motor control signals for human ECoG neuroprosthetics. J Neurosci Methods 167:63-81.

Santhanam G, Ryu SI, Yu BM, Afshar A, Shenoy KV (2006) A highperformance brain-computer interface. Nature 442:195-198.

Santhanam G, Linderman MD, Gilja V, Afshar A, Ryu SI, Meng TH, Shenoy KV (2007) HermesB: a continuous neural recording system for freely behaving primates. IEEE Trans Biomed Eng 54:2037-2350.

Schalk G (2008) Brain-computer symbiosis. J Neural Eng 5:P1-P15.

Schalk G, McFarland DJ, Hinterberger T, Birbaumer N, Wolpaw JR (2004) BCI2000: a general-purpose brain-computer interface (BCI) system. IEEE transactions on bio-medical engineering 51:1034-1043.

Schalk G, Anderson N, Wisneski K, Kim W, Smyth MD, Wolpaw JR, Barbour DL, Leuthardt EC (2007a) Toward brain-computer interfacing using phonemes decoded from electrocorticography activity (ECoG) in humans. Soc Neurosci Abstr 33:414.11.

Schalk G, Kubánek J, Miller KJ, Anderson NR, Leuthardt EC, Ojemann JG, Limbrick D, Moran D, Gerhardt LA, Wolpaw JR (2007b) Decoding two-dimensional movement trajectories using electrocorticographic signals in humans. J Neural Eng 4:264-275.

Schalk G, Miller KJ, Anderson NR, Wilson JA, Smyth MD, Ojemann JG, Moran DW, Wolpaw JR, Leuthardt EC (2008) Two-dimensional movement control using electrocorticographic signals in humans. J Neural Eng 5:75-84.

Serruya MD, Hatsopoulos NG, Paninski L, Fellows MR, Donoghue JP (2002) Instant neural control of a movement signal. Nature 416:141-142.

Seymour JP, Kipke DR (2007) Neural probe design for reduced tissue encapsulation in CNS. Biomaterials 28:3594-3607.

Shain W, Spataro L, Dilgen J, Haverstick K, Retterer S, Isaacson M, Saltzman M, Turner JN (2003) Controlling cellular reactive responses around neural prosthetic devices using peripheral and local intervention strategies. IEEE Trans Neural Syst Rehabil Eng 11:186-188.

Shealy CN, Mortimer JT, Reswick JB (1967) Electrical inhibition of pain by stimulation of the dorsal columns: a preliminary clinical report. Anesth Analg 46:489-491.

Shenoy KV, Meeker D, Cao S, Kureshi SA, Pesaran B, Buneo CA, Batista AP, Mitra PP, Burdick JW, Andersen RA (2003) Neural prosthetic control signals from plan activity. Neuroreport 14:591-596.

Sinai A, Bowers CW, Crainiceanu CM, Boatman D, Gordon B, Lesser RP, Lenz FA, Crone NE (2005) Electrocorticographic high gamma activity versus electrical cortical stimulation mapping of naming. Brain 128:1556-1570.

Sodagar AM, Wise KD, Najafi K (2007) A fully integrated mixed-signal neural processor for implantable multichannel cortical recording. IEEE Trans Biomed Eng 54:1075-1088.

Song YK, Patterson WR, Bull CW, Beals J, Hwang N, Deangelis AP, Lay C, McKay JL, Nurmikko AV, Fellows MR, Simeral JD, Donoghue JP, Connors BW (2005) Development of a chipscale integrated microelectrode/ microelectronic device for brain implantable neuroengineering applications. IEEE Trans Neural Syst Rehabil Eng 13:220-226.

Song YK, Patterson WR, Bull CW, Borton DA, Li Y, Nurmikko AV, Simeral JD, Donoghue JP (2007) A brain implantable microsystem with hybrid $\mathrm{RF} / \mathrm{IR}$ telemetry for advanced neuroengineering applications. Conf Proc IEEE Eng Med Biol Soc 2007:445-448.

Spataro L, Dilgen J, Retterer S, Spence AJ, Isaacson M, Turner JN, Shain W (2005) Dexamethasone treatment reduces astroglia responses to inserted neuroprosthetic devices in rat neocortex. Exp Neurol 194:289-300.

Staba RJ, Wilson CL, Bragin A, Fried I, Engel J Jr (2002) Quantitative analysis of high-frequency oscillations $(80-500 \mathrm{~Hz})$ recorded in human epileptic hippocampus and entorhinal cortex. J Neurophysiol 88:1743-1752.

Suner S, Fellows MR, Vargas-Irwin C, Nakata GK, Donoghue JP (2005) Reliability of signals from a chronically implanted, silicon-based electrode array in non-human primate primary motor cortex. IEEE Trans Neural Syst Rehabil Eng 13:524-541.

Sutter EE (1992) The brain response interface: communication through visually-induced electrical brain responses. J Microcomp App 15:31-45.

Taylor DM, Tillery SI, Schwartz AB (2002) Direct cortical control of 3D neuroprosthetic devices. Science 296:1829-1832.

Vaughan TM, McFarland DJ, Schalk G, Sarnacki WA, Krusienski DJ, Sellers EW, Wolpaw JR (2006) The Wadsworth BCI Research and Development Program: at home with BCI. IEEE Trans Neural Syst Rehabil Eng 14:229-233.

Velliste M, Perel S, Spalding MC, Whitford AS, Schwartz AB (2008) Cortical control of a prosthetic arm for self-feeding. Nature 453:1098-1101.

Wilson JA, Felton EA, Garell PC, Schalk G, Williams JC (2006) ECoG factors underlying multimodal control of a brain-computer interface. IEEE Trans Neural Syst Rehabil Eng 14:246-250.

Wilson MA, McNaughton BL (1993) Dynamics of the hippocampal ensemble code for space. Science 261:1055-1058.

Wise KD, Anderson DJ, Hetke JF, Kipke DR, Najafi K (2004) Wireless implantable microsystems: high-density electronic interfaces to the nervous system. Proc IEEE 92:76-97.

Wolpaw JR, McFarland DJ (1994) Multichannel EEG-based braincomputer communication. Electroencephalogr Clin Neurophysiol 90:444-449.

Wolpaw JR, McFarland DJ (2004) Control of a two-dimensional movement signal by a noninvasive brain-computer interface in humans. Proc Natl Acad Sci U S A 101:17849-17854.

Wolpaw JR, McFarland DJ, Neat GW, Forneris CA (1991) An EEG-based brain-computer interface for cursor control. Electroencephalogr Clin Neurophysiol 78:252-259.

Wolpaw JR, Birbaumer N, McFarland DJ, Pfurtscheller G, Vaughan TM (2002) Brain-computer interfaces for communication and control. Clin Neurophysiol 113:767-791.

Yuen TG, Agnew WF, Bullara LA (1987) Tissue response to potential neuroprosthetic materials implanted subdurally. Biomaterials 8:138-141. 